\title{
Improving Fuel Diesel Efficiency Using Fuel Filter
}

\author{
Tatun Hayatun Nufus ${ }^{1,2}$, Dianta Mustofa Kamal ${ }^{2}$ and Sri Lestari Kusumastuti ${ }^{3}$ \\ 1. Faculty of Agricultural Technology, Bogor Agricultural Institute, Bogor 220, Indonesia \\ 2. Department of Mechanical Engineering, Politeknik Negeri Jakarta, Depok 16425, Indonesia \\ 3. Department of Electrical Engineering, Politeknik Negeri Jakarta, Depok 16425, Indonesia
}

Received: April 18, 2016 / Accepted: April 27, 2016 / Published: June 30, 2016.

\begin{abstract}
The price of fuel oil continues to rise, decreased supplies oil at the other side, both factors increase the interest of researchers to conduct research related to fuel efficiency. Therefore the aim of this study is to improve the efficiency fuel of diesel engine using fuel filter. The method used for the research is testing the most efficient fuel filters made of coil wire coil winding 5,000 , the three distinguished from the coil core diameter of 44.5, 28.5 and $17.5 \mathrm{~mm}$ in diesel engine. The performance test was conducted from $1,100 \mathrm{rpm}$ to $1,700 \mathrm{rpm}$, the throttle opening of $30 \%-60 \%$. The first testing was done by creating a constant speed $1,500 \mathrm{rpm}$ and throttle opening varies from $30 \%$ to $60 \%$, further testing is done by varying the rpm start from $1,100 \mathrm{rpm}$ to 1,700 rpm to make constant valve $40 \%$ and $60 \%$.
\end{abstract}

Key words: Specific fuel consumption, clustering, de-clustering, throttle.

\section{Introduction}

The development technologies for saving fuel today mostly utilize performance of permanent magnets. The fuel in the filter is flowed on the permanent magnet. The disadvantage of the permanent magnetic is power decreasing as the time passed. To enhance the functionality of the fuel filter, then used principle of electric magnetic field of the coil wire on tube filter electrified, the electric current is derived from the battery voltage source [1-3].

The advantages of this type of filter magnetic force continue to function as long as there is electricity. In the first stage of the research, the core diameter of the coil was fixed while the number of coils, the wire diameter and the engine rotation varies, the results obtained with the filter coil of copper wire diameter of $0.15 \mathrm{~mm}$ at high rotation torque 5,500 increased by $8.593 \%$, the average power increased by $10.682 \% \mathrm{CO}$ exhaust gas decreased by $20.207 \%$ and SFC (specific fuel consumption) decreased by $11.805 \%$.

Corresponding author: Dianta Mustofa Kamal, Ph.D., research field: energy.
Bio Savart formula was applied to improve research results. The first stage was making the core diameter coil varies, diameter size of core coil causes the magnetic field generated becomes larger, so the fuel molecules passing through a magnetic field more easily react with oxygen, so that the complete combustion the greater it is $[4,5]$.

Therefore the aim of this study is to improve the efficiency fuel of diesel engine using fuel filter a wide variety of core diameter coils used were 44.5, 28.5 and $17.5 \mathrm{~mm}$, then number of coil windings constant 5,000 with a wire diameter of $0.25 \mathrm{~mm}$ and testing done on diesel engine.

\section{Material and Method}

Material that was used in this research is $0.25 \mathrm{~mm}$ diameter copper wire. The method is:

- Making the fuel filter with $0.25 \mathrm{~mm}$ diameter copper wire and coil wrapped around a core diameter of 17.5, 28.5 and $44.5 \mathrm{~mm}$.

- The next step is testing the performance of the tools that have been made with the test variable is the electromagnet coil wire diameter of $0.25 \mathrm{~mm}$, the 
number of windings electromagnet coil 5,000, the variation in the engine turns $1,300,1,500,1,700$ and $1,900 \mathrm{rpm}$.

- Gas valve opening is made constant $30 \%$, $50 \%$ and $60 \%$. Diesel engine testing is done with a dose of $30 \mathrm{cc}$ of fuel consumption for each engine rotation.

- Source of electric current to the magnetic field is taken from the battery with a voltage of 12 volts.

- Testing is adjusted to predetermined settings in testing diesel engine fuel in Laboratory Department of Mechanical Engineering, Faculty of Engineering, University of Indonesia, Depok. This study uses diesel fuel released by Pertamina. Parameter calculated is the power engine, thermal efficiency, fuel consumption and opacity (black exhaust).

\section{Results and Discussion}

In the Fig. 1 is design of fuel filter in this research. Testing is done by testing a standard machine (without installing equipment designed fuel filter) and by installing a fuel filter in the fuel line diesel engine, with variable testing in accordance with predetermined. From the test results are analyzed to obtain conclusions.

Test equipment specifications: diesel engine tester, type: water cooled 4 cycles, diesel engine. The cylinder-bore $\times$ stroke (piston displacement): $4-83 \times$ $100 \mathrm{~mm}$ (2,163 cc) model: EWS.50, 7,000 rpm.

Fig. 2a shows the relationship of how efficiently the fuel supplied to the engine to be used as power output (SFC), with a variety of opening the throttle valve. The greater the throttle valve opening indicates the load on the engine is too big, it will be related to how much fuel could be a power on the machine. If the SFC is low, indicating economical fuel consumption. The load can be seen opening lower at $30 \%$, the value of SFC by using the filter larger than those not using the tools and the difference is quite large. This marks the opening of the throttle valve use more fuel. $50 \%$ on medium load and high load with openings of $60 \%$, the use of these filters showed the value of SFC is not much different. It shows the use of the tool does not provide a significant influence on the large mass flow rate of fuel that could be a power output of the engine [6-8].

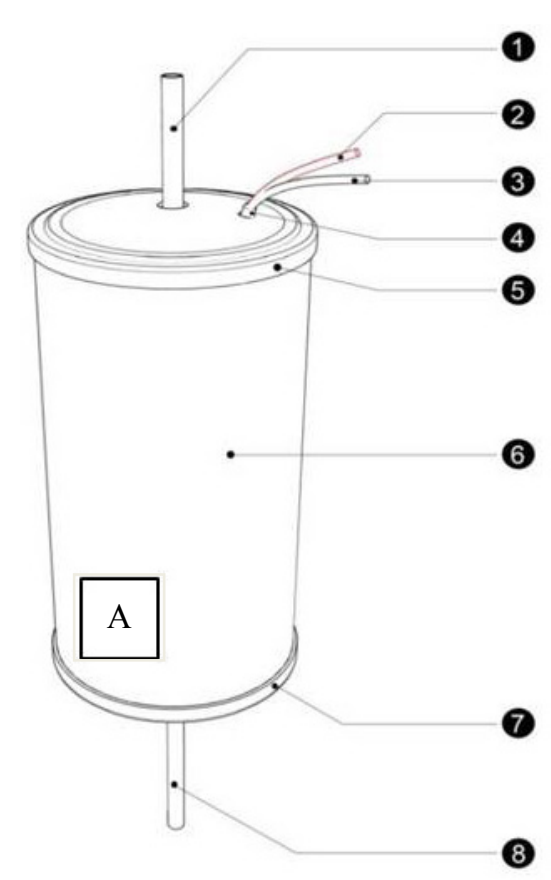

(a)

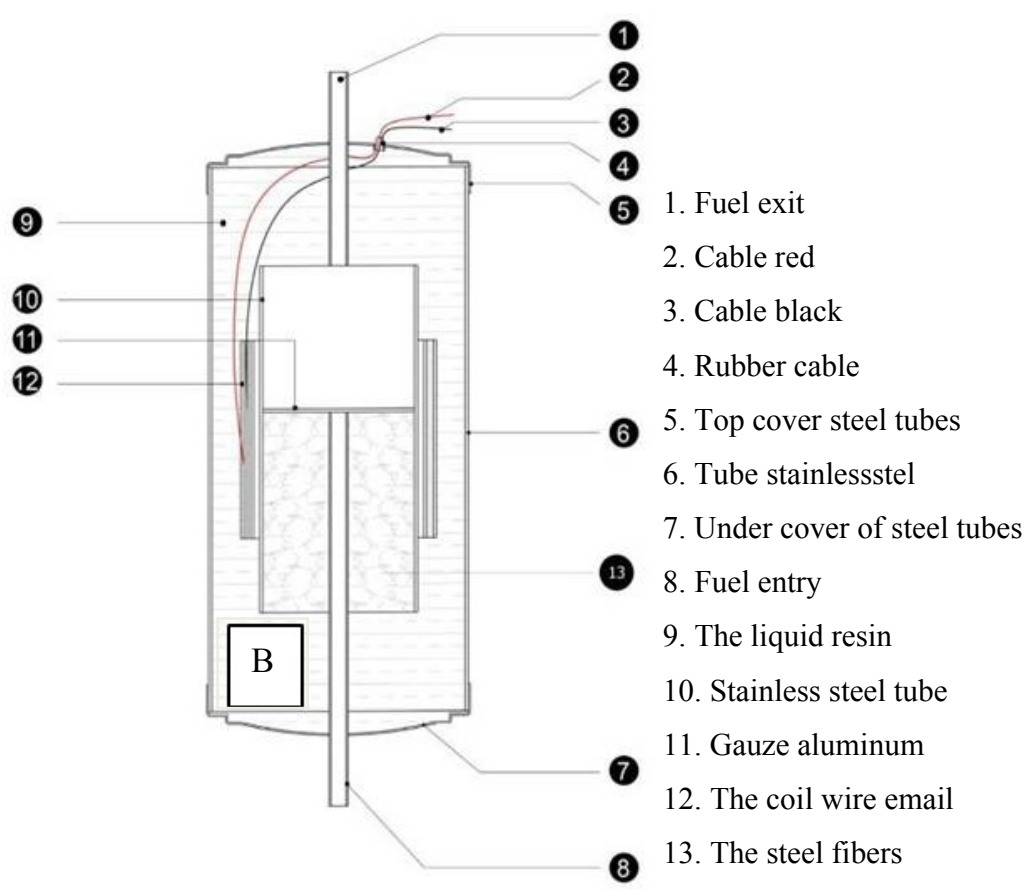

(b)

Fig. 1 (a) Design of fuel filter looked the outside; (b) Looked part in a filter. 


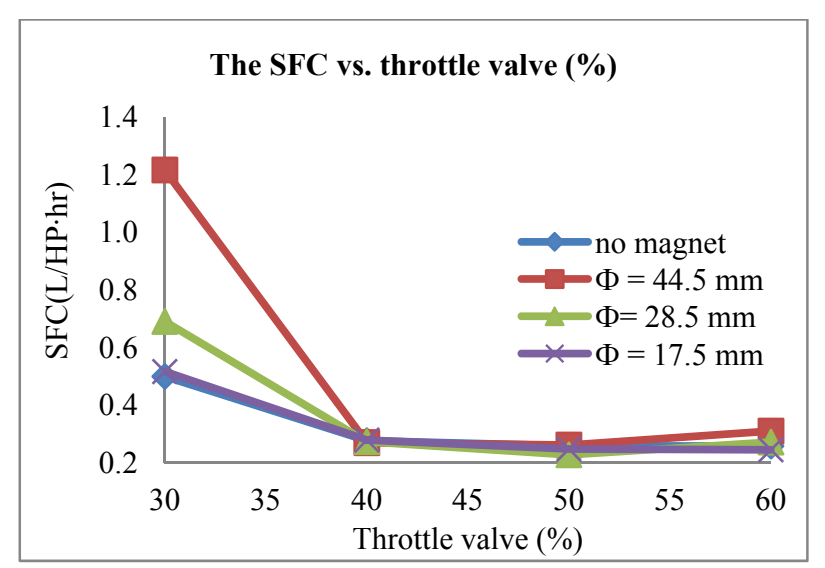

(a)

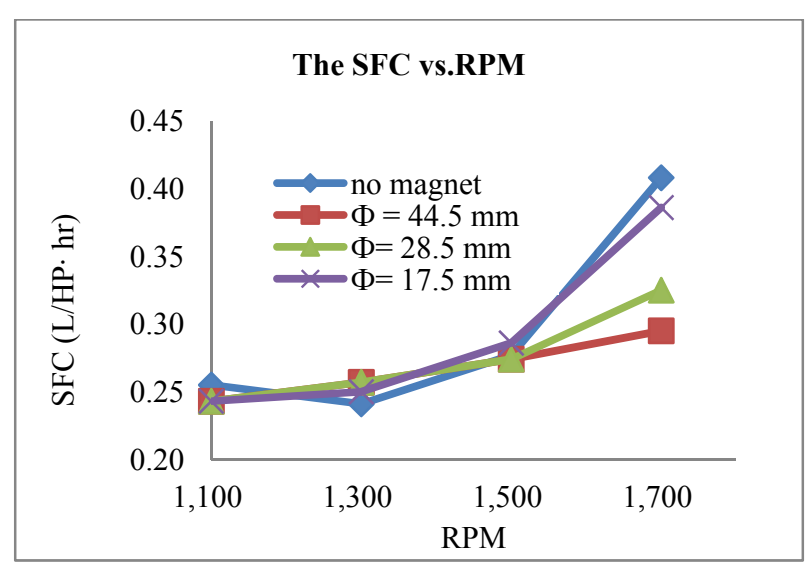

(b)

Fig. 2 (a) SFC vs. throttle valve (rpm 1,500); (b) SFC vs. RPM (throttle valve 40\%).

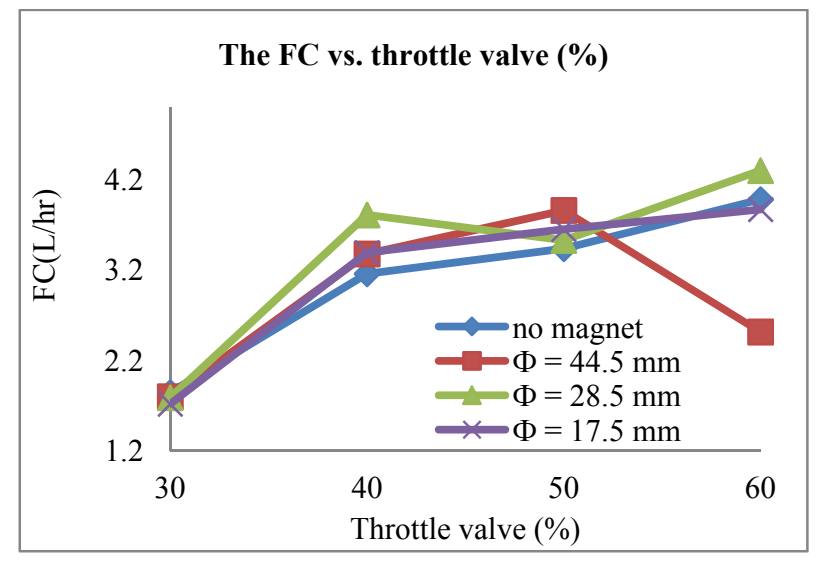

(a)

Fig. 3 (a) FC vs. throttle valve (rpm 1,500); (b) FC vs. RPM.

Fig. $2 \mathrm{~b}$ shows the relationship graph between SFC (specific fuel consumption) and variations in RPM (engine rotation) at the opening throttle valve $40 \%$. At constant throttle valve openings constant, the higher the greater the purists engine load on the engine, and a fuel consumption are increasingly load the greater the resulting engine power decreases [9]. This resulted in specific fuel consumption increases. On lap-lap low and moderate use of the filter tool to demonstrate the value - the value of SFC lower, indicating more efficient fuel use well founded difference is not too significant. But for a higher round is at $1,700 \mathrm{rpm}$ rotation, use the filter tool to demonstrate the value that much more rendahsesuai SFC values above. This shows that, the use of a filter on a higher round gives pengarush quite significant and can be said to be more efficient.

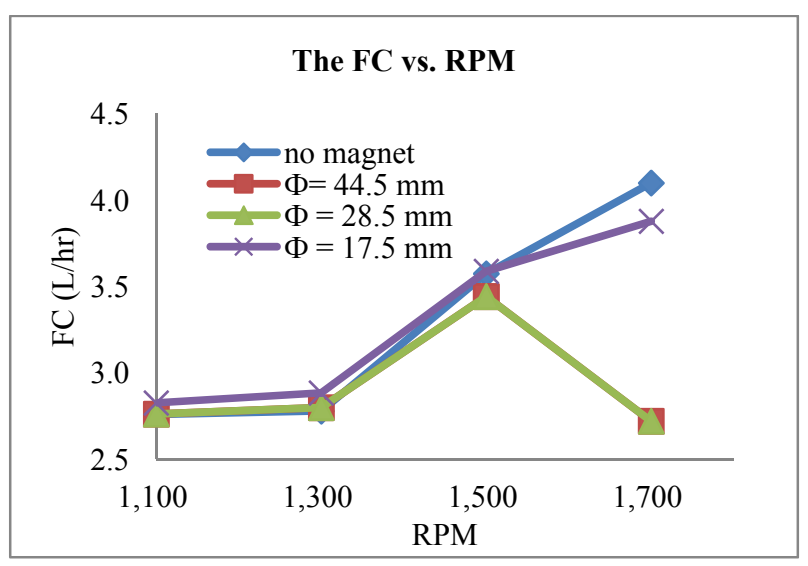

(b)

Fig. 3a shows the relationship between the consumption of fuel by opening the throttle valve at the $1,500 \mathrm{rpm}$ engine speed with or without additional fuel filter. At $30 \%$ throttle valve opened, fuel consumption using filters or not tends to equally good. At the opening of the throttle valve $40 \%$ and $50 \%$, the all filter also showed no significant gains in fuel consumption. Although the filters 2 and 3 did not show any significant results at $60 \%$ throttle opening valve, filter 1 shows the value of fuel consumption is the smallest in the amount of 2,512 L/hr (36\% savings compared to without using filter).

Fig. $3 \mathrm{~b}$ shows the relationship between the consumption of fuel by the engine rotation speed at the throttle valve opening constant at $40 \%$, with or without additional tools. In round 1,100, 1,300 and 


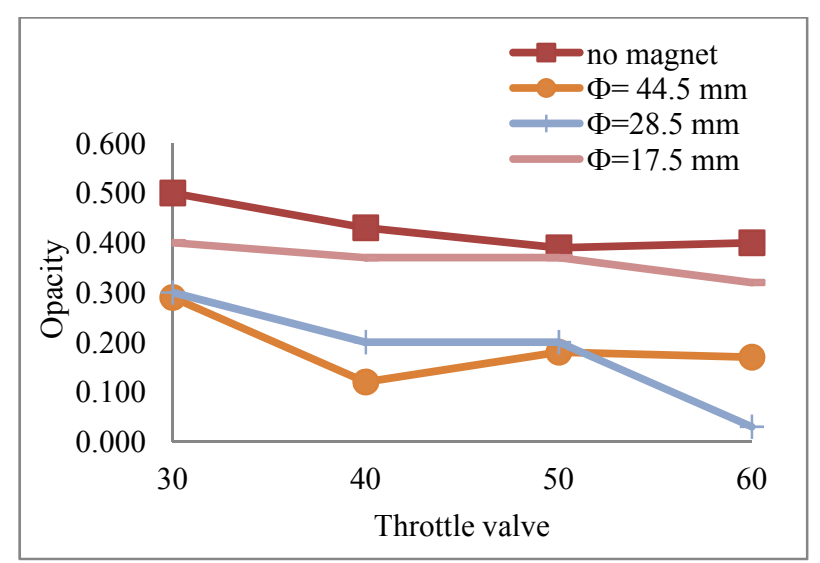

Fig. 4 Opacity vs. throttle valve (rpm 1,500).

1,500 , three devices showed no significant change in fuel consumption.

Fig. 4 shows the relationship between opacity and throttle valve, it can be seen that the opacity is decreased nearly by $40 \%$ when a fuel filter use of magnets on the fuel line for diesel engine [10-12].

Variations in fuel consumption values obtained when $1,700 \mathrm{rpm}$ spin machine. Tools 1 and 2 show the results of significant savings. Tool 2 causes the fuel consumption savings of $28 \%$, the appliance 1 saves fuel consumption by $33 \%$.

Seen with increased load of the throttle valve $30 \%$ to $60 \%$, make the opacity of the use of different filters decreased when compared with unfiltered engine (standard engine). Decrease opacity ranging between $25 \%-60 \%$, and the highest decrease occurred in the filter 2 .

\section{Conclusions}

From the test results and analysis of data obtained can be concluded:

The best filter is the first filter that filters with a diameter of $44.5 \mathrm{~mm}$ coil core at high speed 1,700 $\mathrm{rpm}$, and the valve opening is made constant at $40 \%$ could save fuel by $33 \%$.

Testing is done by creating a constant speed of $1,500 \mathrm{rpm}$ and the valve opening of $60 \%$ is also the best tool to save fuel filter 1 reached $36 \%$, resulting from multiple testing, the greater the applied load and the greater the rotation of the engine occurs, significant difference between the standard engine in comparison with a diesel engine that uses a filter.

Decrease opacity ranges from $25 \%-60 \%$. For each type of fuel-saving devices than the engine without filter.

\section{References}

[1] Andreas, A., and Yuwono, Y. H. 2005. "Evaluation and Redesign Automotive Air Filters Base on Value Engineering and Quality Function Deployment (QFD).” Presented at the Product Design Symposium Atmajaya University, Yogyakarta, Indonesia.

[2] Royer, D. L., Berner, R. A., and Park, J. 2007. "Climate Sensitivity Constrained by $\mathrm{CO}_{2}$ Concentration over the Past 420 Million Years." Nature 446 (March): 530-2.

[3] IPCC (Intergovernmental Panel on Climate Change). 2001. Radioactive Forcing of Climate Change, the Physical Science Basis: Contribution of Work Group I to the Third Asessment Report. Cambridge and New York: IPPC.

[4] Nakicénovic, N., and Swart, R. 2000. IPCC Special Report on Emissions Scenario. Cambridge and New York: Cambridge University Press.

[5] Goode, P. R. 2001. "Earthshine Observations of the Earth's Reflectance." Geophysical Research Letter 28 (9): 1671-4.

[6] Prasetyowati, A. 2008. "Fenomena Pemanasan Global. Asia Pacific Forest Genetic Program."

[7] Jacob, D. J. 1999. Introduction to Atmospheric Chemistry. New Jersey: Princeton University Press.

[8] Dickinson, R. E., and Dalam, C. W., eds. 1982. Carbon Dioxide Review. New York: Clarendon Press, 101-33.

[9] Frochlich, C. 2006. "Solar Irradiance Variability since 1978.” Space Science Reviews 125 (1): 53-5.

[10] Chalid, M., Saksono, N., Adiwar, A., and Darsono, N. 2005. "Dipole Magnetization Effect to Kerosene Characteristics." Makara Journal of Technology 8 (1): 36-42.

[11] Bosch, R., and Adler, U. 1996. Automotive Handbook. USA: Society of Automotive Engineers.

[12] UN-ECE (United Nations Economic Commission for Europe). 1996. "Uniform Provisions Concerning to the Approval of Motorcycle Equipped with a Positive-Ignition with Regard to the Emission of Gaseous Polllutan by the Engine, Regulation No. 40." UN-ECE. 